\title{
Differential effects of malignant mesothelioma cells on THP-1 monocytes and macrophages
}

\author{
VALERIO IZZI $^{1}$, VALERIO CHIURCHIÙ ${ }^{2}$, FABIOLA D'AQUILIO $^{2}$, CAMILLA PALUMBO $^{1}$, \\ ILARIA TRESOLDI $^{1}$, ANDREA MODESTI ${ }^{1}$ and PATRIZIA M. BALDINI ${ }^{2}$ \\ ${ }^{1}$ Department of Experimental Medicine and Biochemical Sciences, University of Rome 'Tor Vergata', \\ Via Montpellier 1; ${ }^{2}$ Department of Biology, University of Rome 'Tor Vergata', \\ Via della Ricerca Scientifica, I-00133 Rome, Italy
}

Received August 7, 2008; Accepted October 2, 2008

DOI: 10.3892/ijo_00000180

\begin{abstract}
Malignant mesothelioma (MM) is a highly fatal tumor arising from inner body membranes, whose extensive growth is facilitated by its week immunogenicity and by its ability to blunt the immune response which should arise from the huge mass of leukocytes typically infiltrating this tumor. It has been reported that the inflammatory infiltrate found in MM tissues is characterized by a high prevalence of macrophages. Thus, in this work we evaluated the ability of human MM cells to modulate the inflammatory phenotype of human THP-1 monocytes and macrophages, a widely used in vitro model of monocyte/macrophage differentiation. Furthermore, we tested the hypothesis that the exposure to MM cells could alter the differentiation of THP-1 monocytes favoring the development of alternatively activated, tumor-supporting macrophages. Our data prove for the first time that MM cells can polarize monocytes towards an altered inflammatory phenotype and macrophages towards an immunosuppressive phenotype. Moreover, we demonstrate that monocytes cocultivated with MM cells 'keep a memory' of their encounter with the tumor which influences their differentiation to macrophages. On the whole, we provide evidence that MM cells exert distinct, cell-specific effects on monocytes and macrophages. The thorough characterization of such effects may be of a crucial importance for the rational design of new immunotherapeutic protocols.
\end{abstract}

\section{Introduction}

Malignant mesothelioma (MM) is a rare tumor which originates from the mesothelial cell linings of the pleura and, less

Correspondence to: Dr Valerio Izzi, Department of Experimental Medicine and Biochemical Sciences, University of Rome 'Tor Vergata', Via Montpellier 1, I-00133 Rome, Italy

E-mail: valerioizzi@libero.it

Key words: malignant mesothelioma, monocytes, macrophages, immunosurveillance, TAMs frequently, peritoneum and pericardium $(1,2)$. Although it has a low metastatic efficiency, MM is highly invasive to surrounding tissues and its extensive growth leads to the failure of the organs underlying the serosal membranes $(1,2)$. The median survival from diagnosis of MM is less than two years $(2,3)$. Indeed, this aggressive tumor is seldom amenable to surgical intervention and poorly responsive to radiotherapy and chemotherapy $(2,3)$. MM is also regarded as a weakly immunogenic tumor, whose ability to escape immune recognition relies on multiple mechanisms (4). Nonetheless, MM tissues are characterized by the presence of massive leukocyte infiltrates, mainly composed of macrophages $(\mathrm{M} \Phi)$, natural killer cells and both $\mathrm{CD}^{+}$and $\mathrm{CD}^{+}$lymphocytes (4).

During recent years, substantial evidence has indicated that under the pressure of tumor microenvironmental factors including growth factors, cytokines and prostaglandins, tumorinfiltrating leukocytes can undergo a dramatic shift in their activities, aborting immunosurveillance and starting to actively support tumor growth, angiogenesis and tissue remodeling $(5,6)$. Tumor-associated $\mathrm{M} \Phi$ (TAMs) appear to play a major role in this regard $(7,8)$. It is well established that М $\Phi$ can act as both positive or negative regulators of the immune system so that, depending on their pro- or anti-inflammatory functional program, mature $\mathrm{M} \Phi$ are classified as $\mathrm{M} 1$, or 'classically activated', or as M2, or 'alternatively activated'. M1 M $\Phi$ are powerful immune effector cells characterized by a high ability to present antigens and to produce proinflammatory cytokines and toxic intermediates, while M2 $\mathrm{M} \Phi$ display a poor antigen-presenting capacity and are polarized to release many different immunosuppressive molecules as well as to promote angiogenesis and extracellular matrix degradation (6-9). It has been indicated that TAMs, which derive almost entirely from circulating monocytes (Mo) recruited and differentiated in the tumor milieu (10-12), often display phenotypic features consistent with those of M2 M $\Phi$ and, accordingly, can actively sustain tumor growth and contribute to generate an immunosuppressive microenvironment $(7,13)$. Moreover, recent evidence demonstrated the existence of Mo with M2-like phenotypes, which could thus be a preferential source of M2 M $\Phi$ and important players in tumor-induced immunosuppression $(10,12)$. 
The definition of the role of individual immune cell types on the outcome of the anti-tumor immune responses is of pivotal importance for the rational design of new antineoplastic immunotherapy approaches. In this respect, however, the functional role of the leukocytes infiltrating MM tissues is still poorly defined (4). Thus, prompted by the reported abundance of infiltrating $\mathrm{M} \Phi$ in $\mathrm{MM}$, we evaluated the ability of human MM cells to modulate the inflammatory phenotype of the THP-1 cell lineage, a widely used in vitro model of Mo/M $\Phi$ differentiation (14). Furthermore, we tested the hypothesis that the exposure to MM cells could alter the differentiation of THP-1 Mo favoring the development of alternatively activated, tumor-supporting МФ.

\section{Materials and methods}

Cell cultures. The human monocytic cell line THP-1 (15) was obtained from the American Type Culture Collection (Manassas, VA, USA). The human pleural MM cell line Mero 84 (16) was a generous gift of Dr Marjan Versnel. Both cell lines were cultured at $37^{\circ} \mathrm{C}$ in $5 \% \mathrm{CO}_{2}$ in DMEM supplemented with $10 \%$ fetal bovine serum (FBS), $2 \mathrm{mM}$ L-glutamine, $100 \mu \mathrm{g} / \mathrm{ml}$ streptomycin, $100 \mathrm{U} / \mathrm{ml}$ penicillin and $100 \mu \mathrm{g} / \mathrm{ml}$ sodium pyruvate (complete medium), all from Cambrex (Lonza Milano, Milan, Italy). THP-1 Mo were differentiated to $\mathrm{M} \Phi$ by incubation with $100 \mathrm{nM}$ phorbol 12-myristate 13-acetate (PMA; Sigma Aldrich, Milan, Italy) for $72 \mathrm{~h}$ in the dark, as previously described (17).

Experimental plan. The effects of MM cells on the phenotype of THP-1 Mo were evaluated using the following experimental plan: THP-1 Mo were seeded in complete medium in 6-well plates at a density of $1-3 \times 10^{5}$ cells/well; each well was then covered with a cell culture insert (pore size: $0.4 \mu \mathrm{M}$; Sigma Aldrich) containing an equal amount of Mero 84 cells seeded in the same medium (THP-1/Mero 84 cell ratio 1:1); after 24,48 or $72 \mathrm{~h}$ of cocultivation, the inserts were removed and the Mo were washed, counted and replated. The cultures containing Mero 84-exposed Mo (Mo-MM) and control cultures containing an equal number of Mo not exposed to Mero 84 cells were then stimulated with $5 \mu \mathrm{g} / \mathrm{ml}$ of LPS (Sigma-Aldrich) for $24 \mathrm{~h}$ and used for comparative phenotypic evaluations.

The effects of MM cells on the phenotype of THP-1 MФ were evaluated using two different experimental settings: in the first setting, THP-1 Mo were differentiated to M $\Phi$ and then cocultivated with Mero 84 cells; in the second setting, Mo were first cocultivated with Mero 84 cells and then differentiated to $\mathrm{M} \Phi$. Cocultures were performed as described above, with a THP-1/Mero 84 cell ratio of $1: 1$.

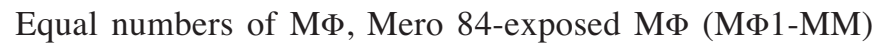
and МФ generated from Mero 84-exposed Mo (MФ2-MM) were then plated and stimulated with $5 \mu \mathrm{g} / \mathrm{ml}$ of LPS for $24 \mathrm{~h}$. The cultures were finally used for comparative phenotypic evaluations as described below.

The growth and survival rate of THP-1 Mo and MФ cultures were routinely assessed by cell counts using the trypan blue exclusion method; proliferation and survival of THP-1 Mo and M $\Phi$ were found to be unaffected by the cocultivation with MM cells and by LPS treatment (data not shown).

$\left[{ }^{3} \mathrm{H}\right]$-arachidonic acid release assay. THP-1 Mo were labelled for $3 \mathrm{~h}$ with $1 \mu \mathrm{Ci}\left[{ }^{3} \mathrm{H}\right]$-arachidonic acid $\left(\left[{ }^{3} \mathrm{H}\right]-\mathrm{AA}\right.$, specific activity 202,4 Ci/mmol; Perkin-Elmer Italia, Monza, Italy) at $37^{\circ} \mathrm{C}$ in serum-free medium, as previously described (18). The labelled cells were then washed twice in serum-free medium to remove unincorporated $\left[{ }^{3} \mathrm{H}\right]-\mathrm{AA}$ and used to obtain replicate cultures of labelled Mo, МФ, Мо-ММ, МФ1-ММ and MФ2-MM. The cultures were finally stimulated with LPS for $24 \mathrm{~h}$. Cultures containing $\left[{ }^{3} \mathrm{H}\right]$-AA-labelled, LPSunstimulated Mo and М $\Phi$ were used to control basal $\left[{ }^{3} \mathrm{H}\right]-\mathrm{AA}$ release. Culture media were collected and $100 \mu \mathrm{l}$ aliquots were added to $3 \mathrm{ml}$ Optifluor (Perkin-Elmer Italia) and analyzed by a liquid scintillator counter.

Measurement of prostaglandin $E_{2}$, tumor necrosis factor- $\alpha$ and interleukin-10 release. The amounts of prostaglandin $\mathrm{E}_{2}$ $\left(\mathrm{PGE}_{2}\right)$, tumor necrosis factor- $\alpha$ (TNF- $\left.\alpha\right)$ and interleukin-10 (IL-10) released in the culture media by LPS-stimulated Mo, МФ, Mo-MM, МФ1-MM and MФ2-MM and by LPSunstimulated Mo and $\mathrm{M} \Phi$, were quantified using a monoclonal $\mathrm{PGE}_{2}$ EIA kit (Cayman Chemicals, Italy Cabru, Arcore, Italy), an ELISA kit for TNF- $\alpha$ and an ELISA kit for IL-10 (both from Pierce Endogen, Celbio, Milan, Italy) according to the manufacturer's instructions.

Evaluation of nitrite production by Griess reaction. The amount of nitrite $\left(\mathrm{NO}_{2}\right)$ released in the culture media of LPS-stimulated Mo, МФ, Mo-MM, МФ1-MM and МФ2MM and of LPS-unstimulated Mo and M $\Phi$ was quantified as previously described (19). Briefly, equal volumes of culture media and Griess modified reagent (Sigma-Aldrich) were mixed in a macrotitre plate. Upon incubation for $30 \mathrm{~min}$ at room temperature, the presence of $\mathrm{NO}_{2}$ in the samples determines the formation of a fluorescent product sensible to stimulation with a laser beam set at $550 \mathrm{~nm}$. $\mathrm{NO}_{2}$ concentration in each sample was thus determined by plotting the sample OD at $550 \mathrm{~nm}$ on a standard curve prepared with sodium nitrite solutions (concentration range 0.43-65 $\mu \mathrm{M}$ ).

Phagocytosis assay. The phagocytic activity of THP-1 cells was evaluated by measuring the uptake of FITC-dextran particles by flow cytometry, as previously described (20). In brief, THР-1 Mo, МФ, Mo-MМ, МФ1-MМ and МФ2-ММ were stimulated with LPS in the presence of $1 \mathrm{mg} / \mathrm{ml}$ FITC-Dextran (MW: $70 \mathrm{kDa}$; Sigma-Aldrich) for $24 \mathrm{~h}$ in the dark. Control Mo and M $\Phi$ were also incubated with FITC-Dextran in the absence of LPS, in order to assess basal phagocytic activity. At the end of incubation, the cells were extensively washed, recovered by centrifugation and analyzed by FACS.

Collagenolytic activity assay. The serum-free culture media of LPS-stimulated Mo, МФ, Mo-MM, МФ1-MM and МФ2-MM and of LPS-unstimulated Mo and $М \Phi$ were collected and 10-fold concentrated using Centricon devices (cut-off: $10 \mathrm{kDa}$; Millipore, Milan, Italy). Aliquots $(200 \mu 1)$ of concentrated 


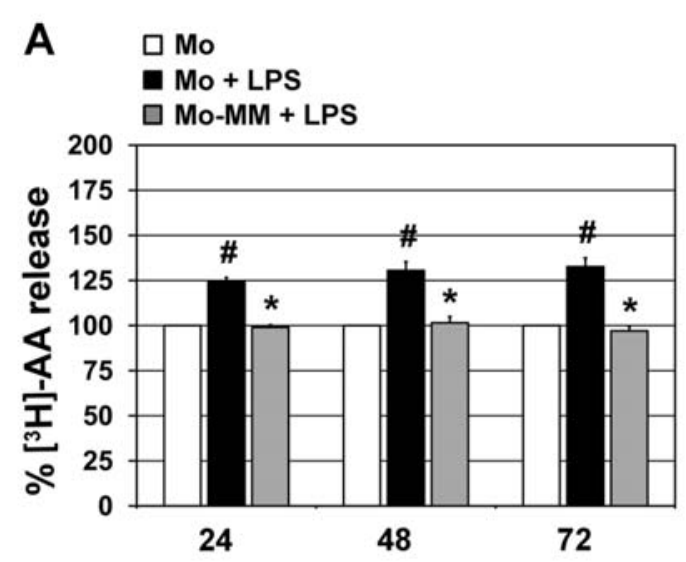

Hours of cocultivation

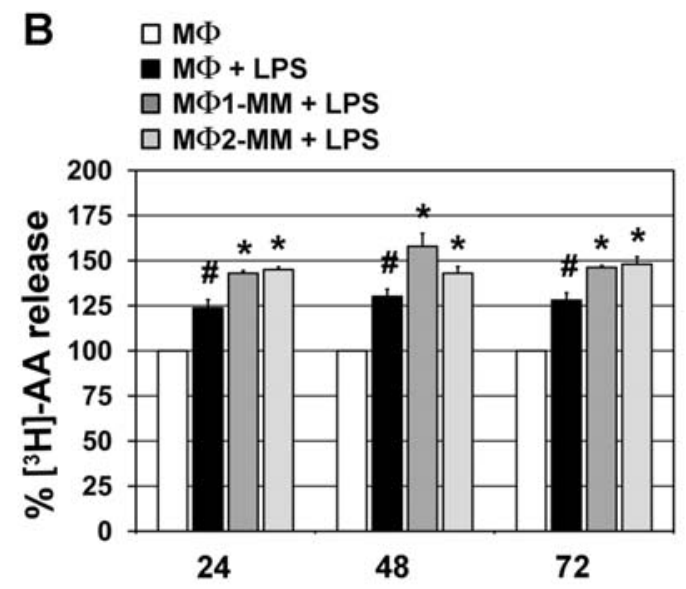

Hours of cocultivation

Figure 1. Effects of MM cells on the release of $\left[{ }^{3} \mathrm{H}\right]-\mathrm{AA}$ by THP-1 Mo and $\mathrm{M} \Phi$. (A) Percentile mean $\pm \mathrm{SD}$ of $\left[{ }^{3} \mathrm{H}\right]-\mathrm{AA}$ release by unstimulated $\mathrm{Mo}$, LPS-stimulated Mo and LPS-stimulated Mo-MM obtained by coculturing Mo with MM cells for 24, 48 and $72 \mathrm{~h}$. (B) Percentile mean \pm SD of [ $\left.{ }^{3} \mathrm{H}\right]-\mathrm{AA}$

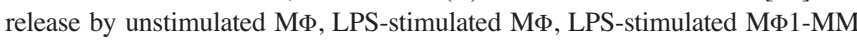
obtained by coculturing Mథ with MM cells for 24-72 h, and LPS-stimulated MФ2-MM generated by Mo cocultured with MM cells for 24-72 $\mathrm{h}$ and then differentiated to $\mathrm{M} \Phi .{ }^{*} \mathrm{p}<0.05$ vs. unstimulated Mo or $\mathrm{M} \Phi$ and ${ }^{*} \mathrm{p}<0.05$ vs. LPS-stimulated Mo or M $\Phi$, as evaluated by ANOVA followed by Newman-Keuls test.

media were mixed with $100 \mu 1$ of fluorescein-labelled collagen (final concentration: $2.5 \mathrm{mg} / \mathrm{ml}$; Sigma-Aldrich) and incubated for $2 \mathrm{~h}$ in the dark at $37^{\circ} \mathrm{C}$. Each mixture was brought to a final volume of $2 \mathrm{ml}$ with phosphate-buffered saline (PBS) and the sample fluorescence was analyzed using a computeraided background-controlling fluorimeter (Perkin-Elmer LS $50 \mathrm{~b}$ ), with the excitation wavelength set at $485 \mathrm{~nm}$, the emission wavelength set at $530 \mathrm{~nm}$, and slits, respectively, set at 5 and $10 \mathrm{~nm}$ for each light pathway (21).

Statistical analysis. Data distribution was preliminarily verified by the Kolmogorov-Smirnov test, and data sets were analyzed by One-way analysis of variance (ANOVA) followed by Newman-Keuls test. Differences were regarded as significant when $\mathrm{p}$-value was $<0.05$. Quantitative data were expressed as the percentile mean \pm SD of at least four replicate determinations, each performed in triplicate, in respect to control levels arbitrary set to 100 , except where otherwise indicated.

\section{Results}

Effects of MM cells on the release of $\left[{ }^{3} \mathrm{H}\right]-A A$ by THP-1 Mo and $M \Phi$. The release of AA from membrane phospholipids is an important marker of Mo and M $\Phi$ activation (22-24). Therefore, in order to characterize the possible immunomodulatory effects exerted by MM cells on the THP-1 lineage, we first evaluated whether the cocultivation with Mero 84 cells could affect the release of $\left[{ }^{3} \mathrm{H}\right]-\mathrm{AA}$ by LPS-stimulated THP-1 Mo and МФ.

As illustrated in Fig. 1A, LPS-stimulated Mo-MM released less $\left[{ }^{3} \mathrm{H}\right]$-AA than LPS-stimulated, non-cocultivated Mo. In particular, the amounts of $\left[{ }^{3} \mathrm{H}\right]-\mathrm{AA}$ released by LPS-stimulated Mo-MM generated by coculturing THP-1 Mo with Mero 84 cells for 24,48 or $72 \mathrm{~h}$ were similar to those released by unstimulated Mo, and about 25\% lower than those of LPSstimulated Mo. Conversely, as illustrated in Fig. 1B, МФ1-MM obtained by coculturing MФ with MM cells for 24-72 h released significantly more $\left[{ }^{3} \mathrm{H}\right]$-AA than non-cocultivated M $\Phi$ in response to LPS. Moreover, also the LPS-stimulated МФ2-MM generated from Mo exposed to MM cells for 24$72 \mathrm{~h}$ released higher amounts of $\left[{ }^{3} \mathrm{H}\right]-\mathrm{AA}$ as compared to LPS-stimulated, non-cocultivated МФ. Since the effects observed after $24-72 \mathrm{~h}$ of cocultivation were similar, a $24 \mathrm{~h}$ cocultivation time was chosen for all subsequent experiments.

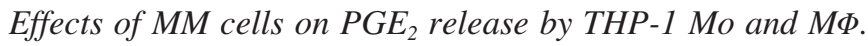
$\mathrm{PGE}_{2}$ is one of the major AA metabolites and it is known to play immunosuppressive functions in the tumor microenvironment $(6,25)$. Thus, it was evaluated whether the cocultivation with Mero 84 cells could modulate the release

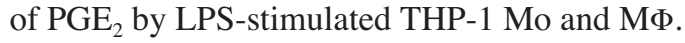

Consistent with the results obtained in $\left[{ }^{3} \mathrm{H}\right]$-AA release studies, the cocultivation with MM cells had opposite effects on the release of $\mathrm{PGE}_{2}$ by THP-1 Mo and M $\Phi$. Indeed, as shown in Fig. 2, LPS-stimulated Mo-MM released lower amounts of $\mathrm{PGE}_{2}$ as compared to non-cocultivated, LPS-stimulated Mo, while the amounts of $\mathrm{PGE}_{2}$ released upon LPS stimulation by both МФ1-MM and МФ2-MM were higher than those released by non-cocultivated $\mathrm{M} \Phi$.

Differential effects of MM cells on TNF- $\alpha$ and IL-10 release. To further evaluate the ability of MM cells to modulate the phenotype of THP-1 cells, experiments were conducted to assess whether the coculture with Mero 84 cells could affect the release of the prototypical pro-inflammatory cytokine TNF- $\alpha$ and the prototypical anti-inflammatory cytokine IL-10 (13) by THP-1 Mo and МФ. Data in Fig. 3A show that the release of TNF- $\alpha$ induced by LPS was about ten-fold lower in Mo-MM vs. the non-cocultivated Mo, while the amounts of IL-10 released in response to LPS by Mo and Mo-MM were similar. Conversely, data in Fig. 3B show that non-cocultivated М $\Phi$, М 1-MM and МФ2-MM released comparable amounts of TNF- $\alpha$ upon LPS stimulation, whereas both МФ1-MM and MФ2-MM showed higher levels of LPS-induced IL-10 release than non-cocultivated $\mathrm{M} \Phi$. 

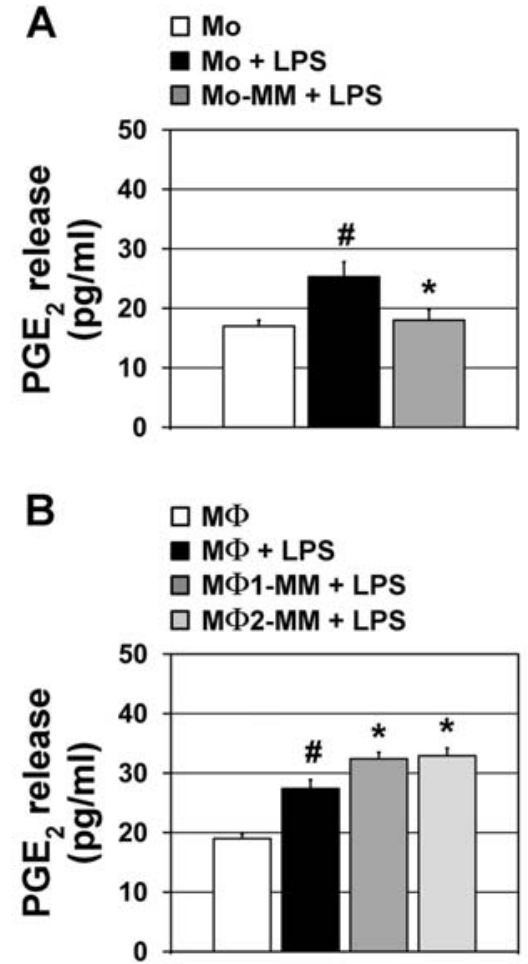

Figure 2. Effects of MM cells on $\mathrm{PGE}_{2}$ release by THP-1 Mo and MФ. (A) Mean $\pm \mathrm{SD}$ values of $\mathrm{PGE}_{2}$ release $(\mathrm{pg} / \mathrm{ml})$ by unstimulated $\mathrm{Mo}$, LPS-stimulated Mo and LPS-stimulated Mo-MM obtained by coculturing Mo with MM cells for $24 \mathrm{~h}$. (B) Mean $\pm \mathrm{SD}$ values of $\mathrm{PGE}_{2}$ release $(\mathrm{pg} / \mathrm{ml})$ by unstimulated M $\Phi$, LPS-stimulated M $\Phi$, LPS-stimulated M $1-\mathrm{MM}$ obtained by coculturing M $\Phi$ with MM cells for $24 \mathrm{~h}$, and LPS-stimulated M 2 2-MM generated by Mo cocultured with MM cells for $24 \mathrm{~h}$ and then differentiated to $\mathrm{M} \Phi .{ }^{*} \mathrm{p}<0.05$ vs. unstimulated $\mathrm{Mo}$ or $\mathrm{M} \Phi$ and ${ }^{*} \mathrm{p}<0.05$ vs. LPS-stimulated Mo or M $\Phi$, as evaluated by ANOVA followed by NewmanKeuls test.

Effects of MM cells on $\mathrm{NO}_{2}$ production. According to different authors, the polarization towards an M2 phenotype is accompanied by a reduction in the capacity to produce NO $(7,26,27)$. In order to assess whether the cocultivation with MM cells could affect the production of NO by THP-1 Mo and $\mathrm{M} \Phi$, the concentration of $\mathrm{NO}_{2}$ in culture media was measured as a surrogate of NO production $(19,28)$. Indeed $\mathrm{NO}_{2}$ is the major metabolite of $\mathrm{NO}$ and its extracellular concentration is directly proportional to that of NO (19).

Data in Fig. 4 show that upon LPS stimulation Mo and Mo-MM produced similar amounts of $\mathrm{NO}_{2}$. On the other hand, both МФ1-MM and МФ2-MM produced lower levels of $\mathrm{NO}_{2}$ than non-cocultivated $\mathrm{M} \Phi$.

Effects of MM cells on Mo and M $\Phi$ phagocytic activity. Next, we focused on the effects of MM cells on the phagocytic properties of THP-1 Mo and M $\Phi$. Data in Fig. 5A show that LPS-stimulated Mo-MM displayed a small increase in the ability to phagocytize FITC-dextran particles as compared to non-cocultivated, LPS-stimulated Mo. However, as illustrated in Fig. 5C this increase did not reach statistical significance. On the other hand, as illustrated in Fig. 5B-D, the phagocytic activity of both МФ1-MM and МФ2-MM was significantly lower than that of non-cocultivated $\mathrm{M} \Phi$ upon LPS-stimulation,
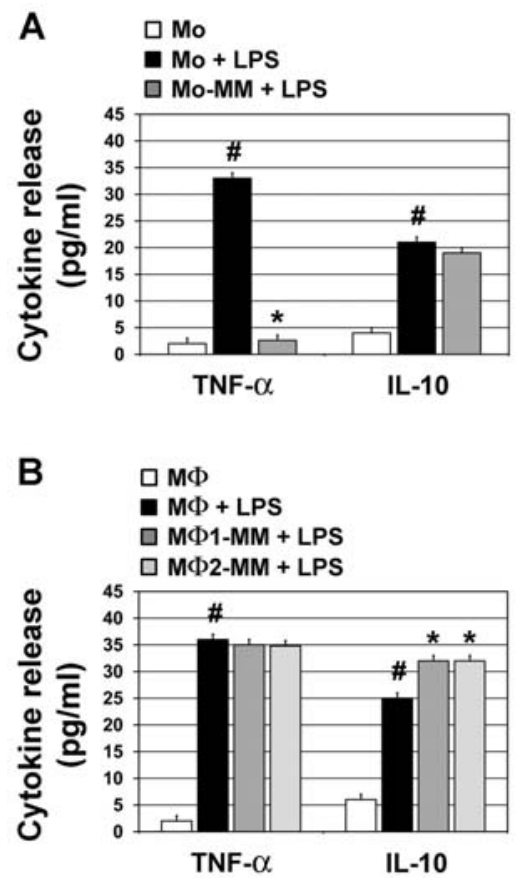

Figure 3. Effects of MM cells on TNF- $\alpha$ and IL-10 release. (A) Mean \pm SD values of TNF- $\alpha$ and IL-10 release $(\mathrm{pg} / \mathrm{ml})$ by unstimulated Mo, LPSstimulated Mo and LPS-stimulated Mo-MM obtained by coculturing Mo with MM cells for $24 \mathrm{~h}$. (B) Mean \pm SD values of TNF- $\alpha$ and IL-10 release (pg/ml) by unstimulated M $\Phi$, LPS-stimulated M $\Phi$, LPS-stimulated M $1-\mathrm{MM}$ obtained by coculturing M $\Phi$ with MM cells for $24 \mathrm{~h}$, and LPS-stimulated МФ2-MM generated by Mo cocultured with MM cells for $24 \mathrm{~h}$ and then differentiated to

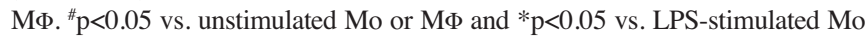
or M $\Phi$, as evaluated by ANOVA followed by Newman-Keuls test.

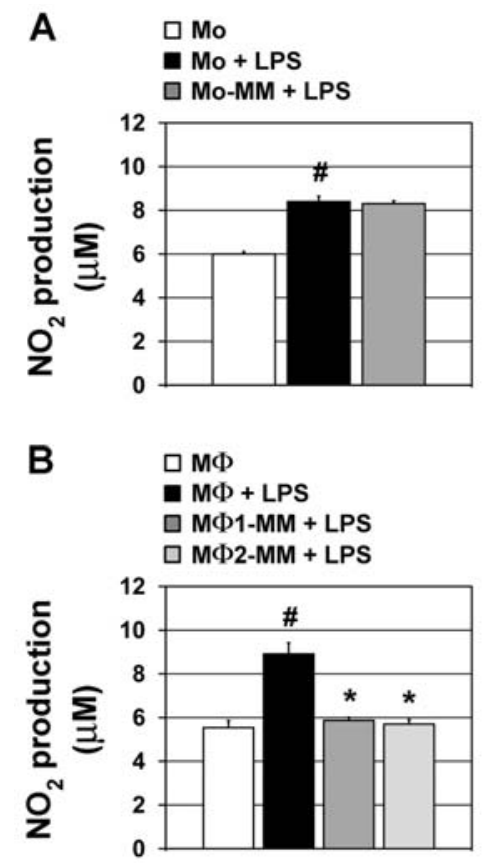

Figure 4. Effects of MM cells on $\mathrm{NO}_{2}$ production. (A) Mean $\pm \mathrm{SD}$ values of $\mathrm{NO}_{2}(\mu \mathrm{M})$ produced by unstimulated Mo, LPS-stimulated Mo and LPS-stimulated Mo-MM obtained by coculturing Mo with MM cells for 24 h. (B) Mean \pm SD values of $\mathrm{NO}_{2}(\mu \mathrm{M})$ produced by unstimulated $\mathrm{M} \Phi$, LPS-stimulated M $\Phi$, LPS-stimulated M $\Phi 1-\mathrm{MM}$ obtained by coculturing M $\Phi$ with MM cells for $24 \mathrm{~h}$, and LPS-stimulated Mథ2-MM generated by Mo cocultured with MM cells for $24 \mathrm{~h}$ and then differentiated to $\mathrm{M} \Phi$. ${ }^{*} \mathrm{p}<0.05$ vs. unstimulated Mo or M $\Phi$ and $* \mathrm{p}<0.05$ vs. LPS-stimulated Mo or $\mathrm{M} \Phi$, as evaluated by ANOVA followed by Newman-Keuls test. 
A

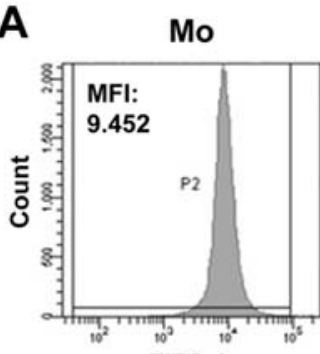

Mo + LPS

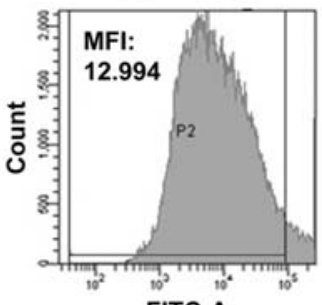

Mo-MM + LPS

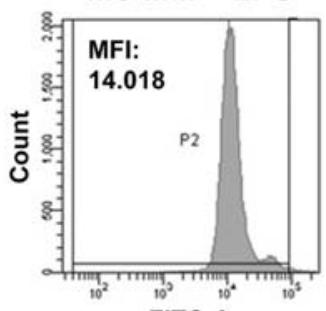

FITC-A

B

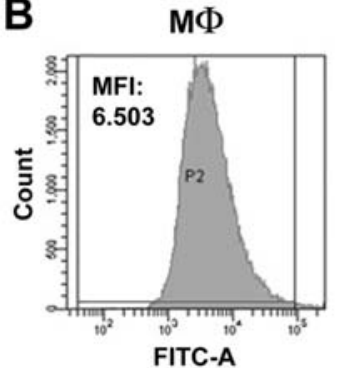

M $\Phi+$ LPS

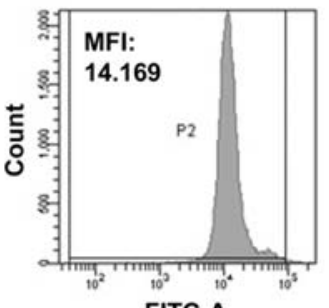

FITC-A

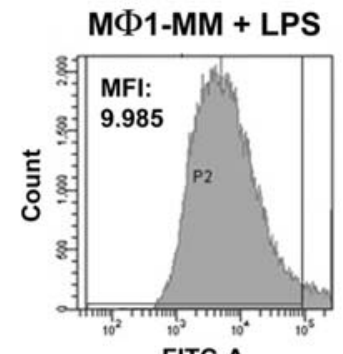

FITC-A
MФ2-MM + LPS

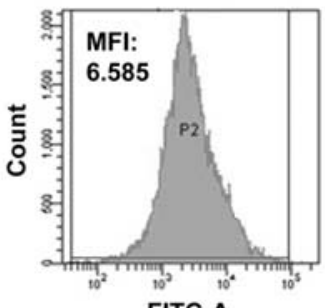

FITC-A
C

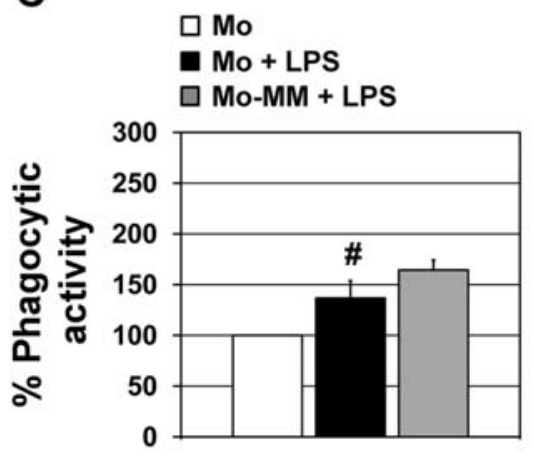

D $\square M \Phi$

- $\mathrm{M} \Phi+$ LPS

口 MФ1-MM + LPS

МФ2-MM + LPS

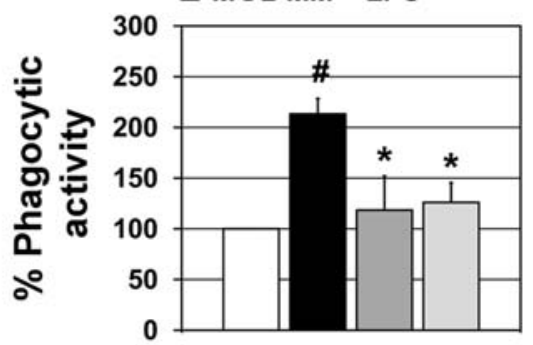

Figure 5. Effects of MM cells on Mo and Mథ phagocytic activity as assessed by flow cytometric analysis of FITC-dextran uptake. (A) A representative determination of FITC-dextran uptake by unstimulated Mo, LPS-stimulated Mo and LPS-stimulated Mo-MM obtained by coculturing Mo with MM cells for $24 \mathrm{~h}$; the mean fluorescence intensity (MFI) is indicated in each case. (B) A representative determination of FITC-dextran uptake by unstimulated M $\Phi$, LPS-stimulated М $\Phi$, LPS-stimulated M 1 1-MM obtained by coculturing М $\Phi$ with MM cells for $24 \mathrm{~h}$, and LPS-stimulated M 2 -MM generated by Mo cocultured with MM cells for $24 \mathrm{~h}$ and then differentiated to M $\Phi$; the MFI is indicated in each case. (C) Percentile mean \pm SD of the phagocytic activity of unstimulated Mo, LPS-stimulated Mo and LPS-stimulated Mo-MM as determined from four different FITC-dextran uptake experiments. (D) Percentile mean \pm SD of the phagocytic activity of unstimulated M $\Phi$, LPS-stimulated M $\Phi$, LPS-stimulated M $\Phi 1-M M$ and M $\Phi 2-M M$ as determined from four different FITC-dextran uptake experiments. ${ }^{*} \mathrm{p}<0.05$ vs. unstimulated Mo or $\mathrm{M} \Phi$ and ${ }^{*} \mathrm{p}<0.05$ vs. LPS-stimulated Mo or M $\Phi$, as evaluated by ANOVA followed by Newman-Keuls test.

Table I. Differential effects of MM cells on the phenotype of LPS-stimulated THP-1 Mo and MФ.

\begin{tabular}{ccc}
$\begin{array}{c}\text { Mo-MM } \\
\text { vs. Mo }\end{array}$ & $\begin{array}{c}\text { МФ1-MM } \\
\text { vs. M } \Phi\end{array}$ & $\begin{array}{c}\text { МФ2-MМ } \\
\text { vs. М } \Phi\end{array}$ \\
\hline
\end{tabular}

\begin{tabular}{lccc}
\hline $\mathrm{AA}$ release & - & + & + \\
$\mathrm{PGE}_{2}$ release & - & + & + \\
$\mathrm{TNF}-\alpha$ release & - & $\mathrm{ns}$ & $\mathrm{ns}$ \\
$\mathrm{IL}-10$ release & $\mathrm{ns}$ & + & + \\
$\mathrm{NO}_{2}$ production & $\mathrm{ns}$ & - & - \\
Phagocytic activity & $\mathrm{ns}$ & - & - \\
Collagenolytic activity & + & + & + \\
\hline
\end{tabular}

+ , significantly increased; -, significantly decreased; ns, not significantly modified. being almost equal to that of unstimulated, non-cocultivated МФ.

MM cells up-regulate the collagenolytic activity of both THP-1 $M o$ and $M \Phi$. Finally, it was assessed whether the cocultivation with MM cells could modulate collagen degradation by THP-1 Mo and M $\Phi$. Interestingly, MM cells exerted comparable effects on the collagenolytic activity of the two cell types. Indeed, as illustrated in Fig. 6, the collagenolytic activity of LPS-stimulated Mo-MM was nearly doubled as compared to that of the non-cocultivated, LPS-stimulated Mo and, similarly, the collagenolytic activity of LPS-stimulated МФ1-MM and МФ2-MМ was more than doubled as compared to that of the non-cocultivated, LPS-stimulated MФ. The reported effects exerted by MM cells on the phenotype of THP-1 Mo and MФ are summarized in Table I. 

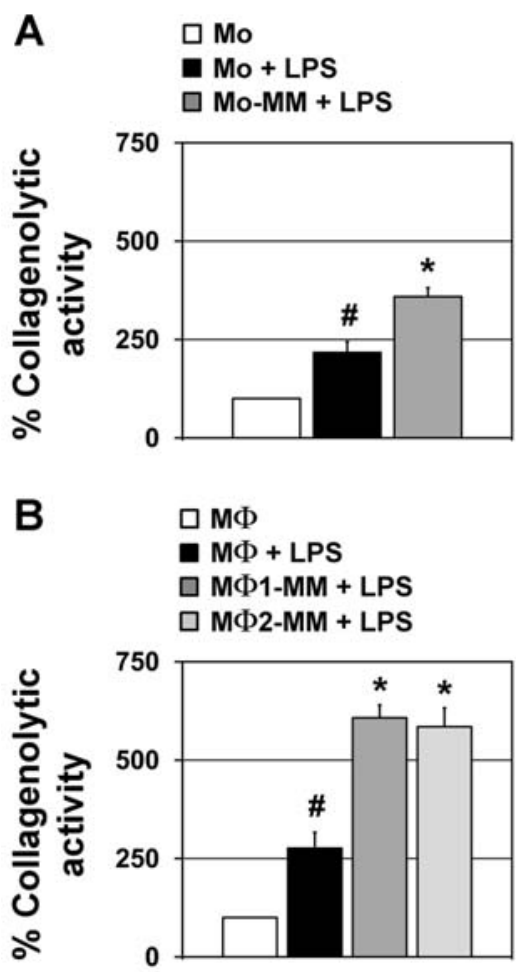

Figure 6. MM cells up-regulate the collagenolytic activity of THP-1 Mo and $\mathrm{M} \Phi$. (A) Percentile mean \pm SD of the collagenolytic activity of unstimulated Mo, LPS-stimulated Mo and LPS-stimulated Mo-MM obtained by coculturing Mo with MM cells for $24 \mathrm{~h}$. (B) Percentile mean \pm SD of the collagenolytic activity of unstimulated M $\Phi$, LPS-stimulated M $\Phi$, LPS-stimulated M 1 1-MM obtained by coculturing M $\Phi$ with MM cells for $24 \mathrm{~h}$, and LPS-stimulated M 2-MM generated by Mo cocultured with MM cells for $24 \mathrm{~h}$ and then differentiated to $\mathrm{M} \Phi$. ${ }^{*} \mathrm{p}<0.05$ vs. unstimulated Mo or $\mathrm{M} \Phi$ and ${ }^{*} \mathrm{p}<0.05$ vs. LPS-stimulated Mo or M $\Phi$, as evaluated by ANOVA followed by NewmanKeuls test.

\section{Discussion}

This report represents the first direct evidence of the broad immunomodulatory effects exerted by pleural MM cells on Mo and МФ. Mononuclear phagocytes are among the earliest immune cells infiltrating tumor sites and they nominally take part to almost all the phases of the anti-tumor reaction (29). In fact, tumor-infiltrating Mo can effectively switch on the inflammatory reaction by releasing chemoattractant and immunostimulating factors and can differentiate into $\mathrm{M} \Phi$, thus empowering the innate response while bridging to the acquired response (29). On the other hand, tumors can develop several strategies to counteract immune effector cells and escape recognition and destruction by the immune system. For instance, many of the soluble factors occurring in the cancer microenvironment are able to suppress the anti-tumor functions of Mo and $\mathrm{M} \Phi$ or even to alter $\mathrm{Mo} / \mathrm{M} \Phi$ functional programs, thus transforming these cells into powerful tumor's allies $(5,29)$.

In the attempt to shed light upon the immunomodulatory activities of MM, we developed a cocultivation framework to evaluate the effects of MM cells on the phenotype of both Mo and M $\Phi$ of the THP-1 lineage. Furthermore, we evaluated whether MM cells could polarize Mo development into immunosuppressive $\mathrm{M \Phi .}$
The first evidence we provide for the immunomodulatory properties of MM cells is represented by their effects on the release of $\left[{ }^{3} \mathrm{H}\right]-\mathrm{AA}$ by THP-1 Mo and M $\Phi$. Indeed our data demonstrate that the cocultivation with MM cells blunts the release of $\left[{ }^{3} \mathrm{H}\right]$-AA by Mo in response to an inflammatory stimulus, while it conversely polarizes $\mathrm{M} \Phi$ to over-release $\left[{ }^{3} \mathrm{H}\right]-\mathrm{AA}$ in response to the same stimulus. Following its release, most AA is metabolized to a large family of proand anti-inflammatory metabolites in a cell-specific manner $(25,30)$. When the LPS-induced release of $\mathrm{PGE}_{2}$, a major AA metabolite with anti-inflammatory properties $(25,31)$ was assessed, it resulted that after the cocultivation with MM cells the amount of $\mathrm{PGE}_{2}$ released by Mo was significantly reduced while, at the opposite, M $\Phi$ displayed a significant up-regulation of $\mathrm{PGE}_{2}$ release. Interestingly, it has been reported that $\mathrm{MM}$ tissues show high levels of $\mathrm{PGE}_{2}$ (32), and that $\mathrm{PGE}_{2}$ production in tumor sites can promote the development of regulatory $\mathrm{T}$ cells (Tregs), which in turn dramatically hamper the effectiveness of the anti-tumor immune response (33).

Further evidence of the differential immunomodulatory effect exerted by MM on the Mo/M $\Phi$ lineage is represented by the cytokine profile expressed by THP-1 Mo and MФ after exposure to MM cells. Following cocultivation with MM cells, the LPS-induced release of the prototypic M1 cytokine TNF- $\alpha$ (13) was markedly decreased in Mo cultures, while it appeared to be unaffected in $M \Phi$ cultures. Conversely, the cocultivation with MM cells enhanced the release of the prototypic M2 cytokine IL-10 (13) by LPSstimulated M $\Phi$, but did not modify the amount of IL-10 released by LPS-stimulated Mo. Moreover, as assessed through the measurement of $\mathrm{NO}_{2}$, the LPS-stimulated release of $\mathrm{NO}$, which is one of the most important tumoricidal molecules produced by the Mo/Mథ lineage (26), was not affected in Mo cocultivated with MM cells, whereas it was significantly reduced in MM-exposed МФ. Collectively, these data indicate that MM cells alter the phenotypic properties of Mo, while more clearly shifting $\mathrm{M} \Phi$ towards an M2-like, protumoral phenotype $(10,13,34)$. The increased production of the immunosuppressive $\mathrm{PGE}_{2}$ and IL-10 and the decrease of NO release observed in MM-exposed $\mathrm{M} \Phi$ are both consistent with a shift towards the acquisition of M2 features $(7,13,27,31)$. Still, this MФ polarization towards an immunosuppressive phenotype was not associated with a reduction in the release of TNF- $\alpha$. Even though TNF- $\alpha$ is considered as a prototypical M1 cytokine, it also displays several tumor-supporting properties, including the ability to promote tumor growth, migration, invasion and angiogenesis (35). Moreover, the production of such a molecule in developing MM foci is thought to mainly depend on $\mathrm{M} \Phi$ and it has been linked to the malignant transformation of mesothelial cells (36). Thus, the observation that the LPS-induced release of TNF- $\alpha$ was not reduced in MM-exposed $\mathrm{M} \Phi$ indicates that, while acquiring immunosuppressive properties, these cells maintain the expression of pro-inflammatory, tumor-supporting mediators.

We also observed that the cocultivation with MM cells had different effects on the phagocytosis of dextran particles by LPS-stimulated Mo and MФ: the phagocytic activity of 
MM-exposed Mo was similar to that of non-cocultivated Mo, whereas the phagocytic activity of MM-exposed M $\Phi$ was significantly reduced as compared to that of non-cocultivated МФ. In view of the results discussed so far, this finding is peculiar. Indeed, according to different authors, alternatively activated $М \Phi$ exhibit a poor antigen-presenting ability but a high capacity for phagocytosis and, accordingly, are efficient scavengers of apoptotic cells and cell debris $(7,37)$. On the other hand, an inefficient clearance of apoptotic cells can elicit pro-inflammatory as well as pro-tumoral, immunosuppressive responses (6). Therefore, the inhibition of the phagocytic activity observed in MM-exposed MФ may play a double-edged role in the modulation of immune functions within the tumor microenvironment.

The observed ability of MM cells to decrease the release of TNF- $\alpha$ and $\mathrm{PGE}_{2}$ without altering the production of IL-10 and $\mathrm{NO}_{2}$ by THP-1 Mo indicates the instauration of an altered phenotype in Mo, which exhibit mixed pro- and antiinflammatory features. It has been reported that tumorassociated Mo can exhibit immunosuppressive, M2-like properties. On the other hand, according to different authors, such Mo appear to display complex and multifaceted phenotypes and may develop from Mo undergoing a transient phase of activation followed by a phase of refractoriness to inflammatory stimuli $(10,34,38,39)$. The altered phenotype displayed by MM-exposed Mo may thus represent an intermediate stage toward the acquisition of more defined immunosuppressive properties.

Remarkably, as assessed by the release of lipid mediators $\left(\left[{ }^{3} \mathrm{H}\right]-\mathrm{AA}, \mathrm{PGE}_{2}\right)$, cytokines (TNF- $\left.\alpha, \mathrm{IL}-10\right)$ and $\mathrm{NO}$ as well as by the phagocytic and collagenolytic activity, the phenotype of THP-1 MФ cocultivated with MM cells (MФ1-MM) was almost identical to that of $\mathrm{M} \Phi$ generated by Mo cocultivated with MM cells (МФ2-MM) for $24 \mathrm{~h}$. This finding demonstrates for the first time that MM-exposed Mo are a 'developmentally polarized' cell type, being yet committed to an altered differentiation after $24 \mathrm{~h}$ of cocultivation with MM cells. These Mo differentiated into immunosuppressive $М \Phi$ in the absence of any further MM-derived factor added during the differentiation process, supporting the hypothesis that altered Mo are a privileged source of M2 МФ.

Collagen degradation is crucially involved in the formation of new vessels as well as in tumor cell migration and invasion (40). Unlike the differential effects discussed above, the cocultivation with MM cells induced a strong up-regulation of the collagen-degrading activity in both LPS-stimulated Mo and $\mathrm{M} \Phi$, demonstrating that either of these cell types can be co-opted by the tumor as an effector of extracellular matrix degradation and tissue remodeling.

Taken together, our data demonstrate that MM polarizes Mo and M $\Phi$ towards distinct phenotypes and that Mo 'keep a memory' of their encounter with the tumor which influences their development to МФ. By suggesting to target Mo in addition to $М \Phi$ (41) for the reversal of tumor-supporting immune cell phenotypes, our data may bear significance for the design of future immunotherapy approaches for MM.

The mechanisms by which tumor cells educate immune cells to exert tumor-supporting functions have not been fully elucidated to date (10). The THP-1/MM cells coculture model could represent a valuable system to investigate the hierarchic role of MM-released factors involved in the modulation of the phenotype of Mo and $\mathrm{M} \Phi$.

\section{Acknowledgements}

We wish to thank Dr Marjan Versnel, Department of Immunology, Erasmus Medical Center, Rotterdam, The Netherlands, for providing the Mero 84 cell line. This work was supported by grants form the Italian Ministry of University and Research (MIUR PRIN 2005) and the Italian Association for Cancer Research (AIRC Regionale 2005).

\section{References}

1. Attanos RL and Gibbs AR: Pathology of malignant mesothelioma. Histopathology 30: 403-418, 1997.

2. Pistolesi M and Rusthoven J: Malignant pleural mesothelioma: update, current management, and newer therapeutic strategies. Chest 126: 1318-1329, 2004.

3. Palumbo C, Bei R, Procopio A and Modesti A: Molecular targets and targeted therapies for malignant mesothelioma. Curr Med Chem 15: 855-867, 2008.

4. Hegmans JP, Hemmes A, Hammad H, Boon L, Hoogsteden HC and Lambrecht BN: Mesothelioma environment comprises cytokines and T-regulatory cells that suppress immune responses. Eur Respir J 27: 1086-1095, 2006.

5. Dunn GP, Bruce AT, Ikeda H, Old LJ and Schreiber RD: Cancer immunoediting: from immunosurveillance to tumor escape. Nat Immunol 3: 991-998, 2002.

6. Kim R, Emi M and Tanabe K: Cancer immunosuppression and autoimmune disease: beyond immunosuppressive networks for tumour immunity. Immunology 119: 254-264, 2006.

7. Sica A, Larghi P, Mancino A, Rubino L, Porta C, Totaro MG, Rimoldi M, Biswas SK, Allavena P and Mantovani A: Macrophage polarization in tumor progression. Semin Cancer Biol Epub ahead of print Mar 26, 2008.

8. Elgert KD, Alleva DG and Mullins DW: Tumor-induced immune dysfunction: the macrophage connection. J Leukoc Biol 64: 275-290, 1998

9. Dirkx AE, Oude Egbrink MG, Wagstaff J and Griffioen AW: Monocyte/macrophage infiltration in tumors: modulators of angiogenesis. J Leukoc Biol 80: 1183-1196, 2006.

10. Kuang DM, Wu Y, Chen N, Cheng J, Zhuang SM and Zheng L: Tumor-derived hyaluronan induces formation of immunosuppressive macrophages through transient early activation of monocytes. Blood 110: 587-595, 2007.

11. Nabil K, Rihn B, Jaurand MC, Vignaud JM, Ripoche J, Martinet Y and Martinet N: Identification of human complement factor $\mathrm{H}$ as a chemotactic protein for monocytes. Biochem J 326: 377-383, 1997.

12. Martinet N, Beck G, Bernard V, Plenat F, Vaillant P, Schooneman F, Vignaud JM and Martinet Y: Mechanism for the recruitment of macrophages to cancer site. In vivo concentration gradient of monocyte chemotactic activity. Cancer 70: 854-860, 1992.

13. Van Ginderachter JA, Movahedi K, Hassanzadeh Ghassabeh G, Meerschaut S, Beschin A, Raes G and De Baetselier P: Classical and alternative activation of mononuclear phagocytes: picking the best of both worlds for tumor promotion. Immunobiology 211: 487-501, 2006.

14. Auwerx J: The human leukemia cell line, THP-1: a multifaceted model for the study of monocyte-macrophage differentiation. Experientia 47: 22-31, 1991.

15. Tsuchiya S, Yamabe M, Yamaguchi Y, Kobayashi Y, Konno T and Tada K: Establishment and characterization of a human acute monocytic leukemia cell line (THP-1). Int J Cancer 26: 171-176, 1980.

16. Versnel MA, Bouts MJ, Hoogsteden HC, van der Kwast TH, Delahaye $\mathrm{M}$ and Hagemeijer A: Establishment of human malignant mesothelioma cell lines. Int J Cancer 44: 256-260, 1989.

17. Tsuchiya S, Kobayashi Y, Goto Y, Okumura H, Nakae S, Konno $\mathrm{T}$ and Tada $\mathrm{K}$ : Induction of maturation in cultured human monocytic leukemia cells by a phorbol diester. Cancer Res 42: 1530-1536, 1982. 
18. Donchenko V, Zannetti A and Baldini PM: Insulin-stimulated hydrolysis of phosphatidylcholine by phospholipase $\mathrm{C}$ and phospholipase D in cultured rat hepatocytes. Biochim Biophys Acta 1222: 492-500, 1994.

19. Pèrez-Pèrez GI, Shepherd VL, Morrow JD and Blaser MJ: Activation of human THP-1 cells and rat bone marrow-derived macrophages by Helicobacter pylori lipopolysaccharide. Infect Immun 63: 1183-1187, 1995.

20. Kato M, Neil TK, Fearnley DB, McLellan AD, Vuckovic S and Hart DN: Expression of multilectin receptors and comparative FITC-dextran uptake by human dendritic cells. Int Immunol 12: 1511-1519, 2000.

21. Ikeda U, Shimpo M, Ohki R, Inaba H, Takahashi M, Yamamoto K and Shimada K: Fluvastatin inhibits matrix metalloproteinase-1 expression in human vascular endothelial cells. Hypertension 36: 325-329, 2000

22. Dennis EA, Ackermann EJ, Deems RA and Reynolds LJ: Multiple forms of phospholipase A2 in macrophages capable of arachidonic acid release for eicosanoids biosynthesis. Adv Prostaglandin Thromboxane Leukoc Res 23: 75-80, 1995.

23. Chiurchiù V, Izzi V, D'Aquilio F, Carotenuto F, Di Nardo $P$ and Baldini PM: Brain natriuretic peptide (BNP) regulates the production of inflammatory mediators in human THP-1 macrophages. Regul Pept 148: 26-32, 2008.

24. Oestvang J, Anthonsen MW and Johansen B: Role of secretory and cytosolic phospholipase A(2) enzymes is lysophosphatidylcholine-stimulated monocyte arachidonic acid release. FEBS Lett 555: 257-262, 2003.

25. Wang MT, Honn KV and Nie D: Cyclooxygenases, prostanoids, and tumor progression. Cancer Metastasis Rev 26: 525-534, 2007.

26. Wink DA, Vodovotz Y, Laval J, Laval F, Dewhirst MW and Mitchell JB: The multifaceted roles of nitric oxide in cancer. Carcinogenesis 19: 711-721, 1998.

27. Weigert A and Brüne B: Nitric oxide, apoptosis and macrophage polarization during tumor progression. Nitric oxide 19: 95-102, 2008.

28. Frank JA, Wray CM, McAuley DF, Schwendener R and Matthay MA: Alveolar macrophages contribute to alveolar barrier dysfunction in ventilator-induced lung injury. Am J Physiol Lung Cell Mol Physiol 291: L1191-L1198, 2006.

29. Smyth MJ, Dunn GP and Schreiber RD: Cancer immunosurveillance and immunoediting: the roles of immunity in suppressing tumor development and shaping tumor immunogenicity. Adv Immunol 90: 1-50, 2006.
30. Seeds MC and Bass DA: Regulation and metabolism of arachidonic acid. Clin Rev Allergy immunol 17: 5-26, 1999.

31. Harizi $\mathrm{H}$ and Gualde N: Pivotal role of $\mathrm{PGE}_{2}$ and IL-10 in the cross-regulation of dendritic cell-derived inflammatory mediators. Cell Mol Immunol 3: 271-277, 2006.

32. Edwards JG, Faux SP, Plummer SM, Abrams KR, Walker RA, Waller DA and O'Byrne KJ: Cyclooxygenase-2 expression is a novel prognostic factor in malignant mesothelioma. Clin Cancer Res 8: 1857-1862, 2002.

33. Sharma S, Yang SC, Zhu L, Reckamp K, Gardner B, Baratelli F, Huang M, Batra RK and Dubinett SM: Tumor cyclooxygenase2/prostaglandin E2-dependent promotion of FOXP3 expression and $\mathrm{CD} 4^{+} \mathrm{CD} 25^{+} \mathrm{T}$ regulatory cell activities in lung cancer. Cancer Res 65: 5211-5220, 2005.

34. Gallina G, Dolcetti L, Serafini P, De Santo C, Marigo I, Colombo MP, Basso G, Brombacher F, Borrello I, Zanovello P, Bicciato S and Bronte V: Tumors induce a subset of inflammatory monocytes with immunosuppressive activity on $\mathrm{CD} 8^{+} \mathrm{T}$ cells. J Clin Invest 116: 2777-2790, 2006.

35. Mocellin S and Nitti D: TNF and cancer: the two sides of the coin. Front Biosci 13: 2774-2783, 2008.

36. Carbone $\mathrm{M}$ and Bedrossian CW: The pathogenesis of mesothelioma. Semin Diagn Pathol 23: 56-60, 2006.

37. Xu W, Roos A, Schlagwein N, Woltman AM, Daha MR and van Kooten C: IL-10-producing macrophages preferentially clear early apoptotic cells. Blood 107: 4930-4937, 2006.

38. Movahedi K, Guilliams M, Van den Bossche J, van den Bergh R, Gysemans C, Beschin A, De Baetselier P and van Ginderachter JA: Identification of discrete tumor-induced myeloid-derived suppressor cell subpopulations with distinct $\mathrm{T}$ cell-suppressive activity. Blood 111: 4233-4244, 2008.

39. Umemura N, Saio M, Suwa T, Kitoh Y, Bai J, Nonaka K, Ouyang GF, Okada M, Balazs M, Adany R, Shibata T and Takami T: Tumor-infiltrating myeloid-derived suppressor cells are pleiotropic-inflamed monocytes/macrophages that bear M1and M2-type characteristics. J Leukoc Biol 83: 1136-1144, 2008.

40. Jodele S, Blavier L, Yoon JM and De Clerck YA: Modifying the soil to affect the seed: role of stromal-derived matrix metalloproteinases in cancer progression. Cancer Metastasis Rev 25: 35-43, 2006.

41. Miselis NR, Wu ZJ, van Rooijen N and Kane AB: Targeting tumor-associated macrophages in an orthotopic murine model of diffuse malignant mesothelioma. Mol Cancer Ther 7: 788-799, 2008. 